\title{
EBV-associated post-transplantation B-cell lymphoproliferative disorder following allogenic stem cell transplantation for acute lymphoblastic leukaemia: tumor regression after reduction of immunosuppression - a case report
}

\author{
Alexander Krenauer ${ }^{1}$, Alexander Moll' ${ }^{1}$ Wolfram Pönisch², Nicole Schmitz ${ }^{1}$, Gerald Niedobitek ${ }^{3}$, \\ Dietger Niederwieser ${ }^{2}$, Thomas Aigner ${ }^{1 *}$
}

\begin{abstract}
Epstein-Barr virus (EBV)-associated B-cell post-transplantation lymphoproliferative disorder (PTLD) is a severe complication following stem cell transplantation. This is believed to occur as a result of iatrogenic immunosuppression leading to a relaxation of T-cell control of EBV infection and thus allowing viral reactivation and proliferation of EBV-infected B-lymphocytes. In support of this notion, reduction of immunosuppressive therapy may lead to regression of PTLD.

We present a case of an 18-year-old male developing a monomorphic B-cell PTLD 2 months after receiving an allogenic stem cell transplant for acute lymphoblastic leukemia. Reduction of immunosuppressive therapy led to regression of lymphadenopathy. Nevertheless, the patient died 3 months afterwards due to extensive graft-vs.-hostdisease and sepsis. As a diagnostic lymph node biopsy was performed only after reduction of immunosuppressive therapy, we are able to study the histopathological changes characterizing PTLD regression. We observed extensive apoptosis of blast cells, accompanied by an abundant infiltrate comprising predominantly CD8-positive, Granzyme B-positive T-cells. This observation supports the idea that regression of PTLD is mediated by cytotoxic T-cells and is in keeping with the observation that T-cell depletion, represents a major risk factor for the development of PTLD.
\end{abstract}

\section{Introduction}

The Epstein-Barr virus (EBV), a human herpes virus, was first discovered in 1964 in cultured tumour cells from Burkitt lymphoma [1]. Subsequently, EBV was shown to be ubiquitously distributed, infecting over $90 \%$ of the adult human population world wilde. Upon primary infection, B-cells are immortalized and driven into proliferation. Viral infection in B-cells usually remains latent, i.e., infectious virus is not produced, and is characterised by the expression of several viral proteins, notably EBV-encoded nuclear antigen (EBNA) 2 and latent membrane protein (LMP) 1 , which are thought to orchestrate virus-induced immortalisation and

\footnotetext{
* Correspondence: th.aigner@yahoo.de
'Institute of Pathology, University of Leipzig, Liebigstr. 26, 04103 Leipzig,

* Correspondence: th.aigner@yahoo.de
'Institute of Pathology, University of Leipzig, Liebigstr. 26, 04103 Leipzig, Germany
}

proliferation of B-cells. As a consequence, EBV-specific cytotoxic (CD8-positive) T-cells are generated which control EBV infection and lead to the establishment of an asymptomatic life-long virus persistence in memory B-cells with minimal viral gene expression. This, however, can change in transplant recipients in whom iatrogenic immunosuppression leads to a relaxation of $\mathrm{T}$-cell control of EBV infection allowing the re-emergence of proliferating EBV-infected B-cells and leading to posttransplantation lymphoproliferative disorders (PTLDs) (for review see Hsieh 1999 and Loren 2003 [2,3]). According to the WHO classification PTLD comprise five subtypes, i.e., early lesions (plasmacytic hyperplasia and infectious mononucleosis-like PTLD), polymorphic PTLD, monomorphic B-cell PTLD, monomorphic T/NK-cell PTLD and classical Hodgkin lymphoma-like 
PTLD with the first two representing EBV-driven B-cell proliferations [4] of poly- and monoclonal origin. Risk factors for the development of a PTLD after HSCT (human stem cell transplantation) include $\mathrm{T}$-cell depletion, age, HLA-mismatch, specific antilymphocyte antigraft-versus-host disease therapies, splenectomy and HSCT for primary immunodeficiency disorders $[2,3]$. The treatment options for B-cell PTLDs include reduction of immunosuppression, antiviral therapy, interferon alpha therapy, CD20 antibody therapy and chemotherapy.

In this report, we present a case of EBV-associated PTLD following allogenic stem cell transplantation for acute lymphoblastic leukemia with evidence of tumor regression subsequent to reduction of immunosuppression, showing for the first time the histopathological changes within lymph nodes after reduction of immunosuppression.

\section{Clinical Case}

An 18-year-old male patient presented with tiredness, night sweats, dyspnoea at exercise and shivering. The

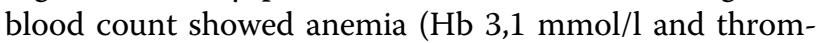
bocythopenia (thrombocytes 143/nl). The white blood cell count and the differential blood smear were normal (leukocytes $6800 / \mu \mathrm{l}$ : granulocytes $60 \%$; lymphocytes $36 \%$; monocytes $2 \%$; eosinophils $2 \%$; blasts not detectable).

A diagnosis of acute lymphoblastic leukemia (L2 according to the FAB classification) was made based on bone marrow trephine biopsy showing dense lymphoblastic infiltrates (about 90\%) with a severely reduced residual haematopoiesis. The tumor cells were positive for CD19 and cytoplasmatic IgM as well as CD10, CD34 and TdT consistent with ALL. The myeloid marker CD13 was aberrantly coexpressed. No expression was observed for CD3. FACS analysis showed predominantly immature B-lymphocytes, strongly positive for CD34 and CD10 confirming the diagnosis of a common-B-ALL. PCR-analysis revealed no evidence of BCR-ABL fusion transcripts.

Immediately after diagnosis, primary chemotherapy was started with dexamethasone, cyclophosphamide and methotrexate $15 \mathrm{mg}$ intrathecally for 5 days. Subsequently, an induction chemotherapy phase I according to the GMALL 07/2003 protocol (German Multicenter Study Group for Adult ALL) was performed with dexamethasone, vincristine, daunorubicine and asparaginase. During the induction therapy a prophylactic irradiation of the central nervous system was performed (24 Gy). Complete remission was achieved. However, since FACS analysis of the bone marrow showed a residual common-B-ALL population of $2 \%$, consolidation therapy (according to GMALL) was completed and an unrelated allogenic stem cell donor was identified (HLA-status: A, B, DRB1, DQB1 identical, C: mismatch).
Eight months after the initial diagnosis, allogenic peripheral stem cell transplantation was performed: the conditioning regimen consisted of $12 \mathrm{~Gy}$ total body irritation in 6 fractions with shielding of the lungs (10Gy), cyclophosphamide dose $60 \mathrm{mg} / \mathrm{kg} / \mathrm{d}$ at 2 days and ATG (rabbit) $1000 \mathrm{mg} / \mathrm{d}=14,7 \mathrm{mg} / \mathrm{kg} / \mathrm{d}$ at day -4 to -1 before first PSCT. Graft-versus-host prophylaxis consisted of cyclosporin A, MTX and prednisolon. Whereas no early complications were noted, mucositis later required parenteral alimentation. Because of fever of unknown origin the patient was treated with antibiotics for 28 days after transplantation, when the patient was referred to a rehabilitation center.

Seven weeks post-transplantation, the patient developed fever (up to $39^{\circ} \mathrm{C}$ ) and a rapidly progressing painful lymphadenopathy at multiple sites (submandibular, axillar and inguinal). $\mathrm{CrP}$ and creatinine increased and he developed leuko- and thrombocytopenia: He was therefore was referred to the hospital for further diagnosis. Medication at transferral included diflucane 200 (fluconazol $200 \mathrm{mg}$ ) twice a day i.v. and ceftriaxone $2 \mathrm{~g}$ i.v. per day. The dose of sandimmune optoral was reduced from $150 \mathrm{mg}$ to $100 \mathrm{mg}$ upon arrival at the hospital. An infection with EBV and a reactivation of CMV could be confirmed with PCR-analysis of peripheral blood and after medication with zovirax ${ }^{\bullet}$ (acyclovir), cymevene $^{\bullet}$ (gancyclovir) was used for therapy for 9 days (was heißt das genau?). Subsequently, the CMV and EBV-PCR was negative again.

Atypical lymphocytes were found in the peripheral blood. FACS- analysis showed no evidence of recurrent pre-B-ALL suggesting virus-induced alterations. A high percentage of activated T-cells and a marked shift of T-cell subpopulations (CD4/CD8: 0,03) were conspicuous. Histopathological examination of bone marrow trephine biopsy showed a moderately hypocellular bone marrow with borderline maturation abnormalities of erythro- and megakaryopoesis, reactive eosinophilia and increased siderin in histiocytic cells. No lymphocytic or lymphoblastic infiltrates were detectable. Overall, the histological picture was considered to be consistent with drug-induced bone marrow toxicity.

CT-scan showed splenic enlargement and cervical, axillary, inguinal and abdominal lymphadenopathy. The brain was normal with no evidence of tumor infiltration.

Cervical lymph node biopsy was performed 1 week after transferral to the hospital and 1 week subsequent to the reduction of immunosuppressive therapy. This revealed complete effacement of lymph node architecture (fig. 1a-c) due to infiltration by CD20-positive lymphoid blasts (Fig. 1d) with high proliferative activity (Mib-1 80-90\%: fig. 1l). The vast majority of infiltrating cells were EBV-positive as demonstrated by EBER-specific in situ hybridisation (not shown). Scattered blast 

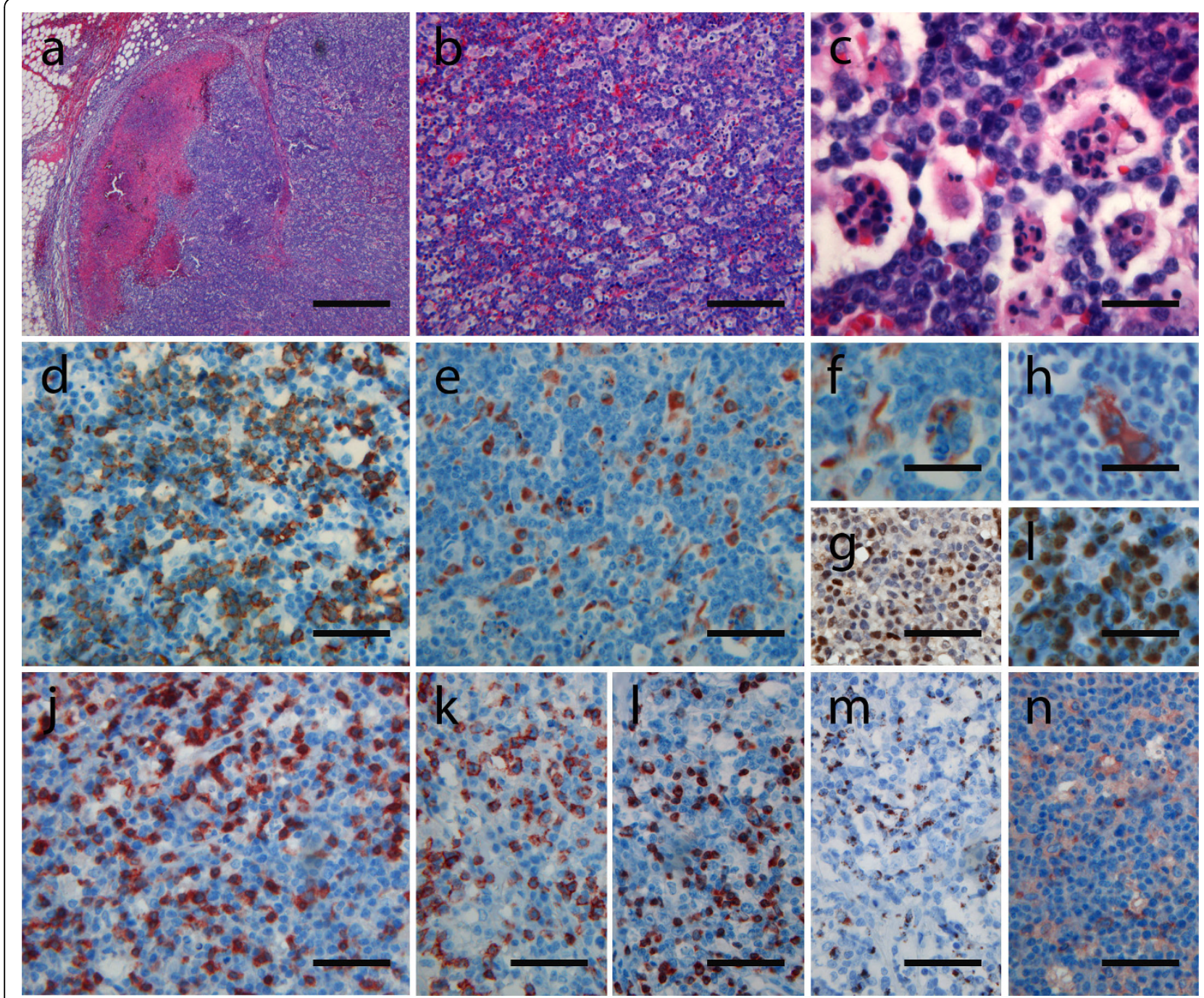

Figure 1 On conventional HE staining a lymph node with vanished lymph node structure and focal necrosis and perinodal lymphatic infiltrates were seen (a). At higher magnification (b, $c$ ), a blastic infiltrate with strong apoptotic activity and many macrophages engulfing apoptotic nuclear bodes were visible. Immunolabeling confirmed the B-cellular lineage of most blastic cells (d: CD20) with macrophages cells lying in between (e+f: CD68). Part of the blastic cells was positive for EBNA2 (g) and EBV late membrane antigen (h: LMP). Overall, there was a high proliferative activity (i: Mib-1 positivity in about 80-90\% of B-blasts). Additionally, a lot of CD3 (j)/CD8 (k) positive T-cells were interspersed, with hardly any CD4-positive T-helper cells identifiable (l). The T-cells were positive for perforin $(\mathrm{m})$ and granzyme B (n). (a-c: hematoxylin eosin stainings; d-n: immunostainings with the antibodies indicated above) (magnification bars: a: $500 \mu \mathrm{m} ; \mathrm{b}: 100 \mu \mathrm{m} ; \mathrm{c}: 22 \mu \mathrm{m} ; \mathrm{d}, \mathrm{e}, \mathrm{g}, \mathrm{i}-\mathrm{n}: 50 \mu \mathrm{m}$; f, h, I: $40 \mu \mathrm{m})$.

cells were positive for EBNA2 (fig. 1g) as well as LMP1 (fig. 1h), indicating a type III of EBV latency. PCR analysis showed a monoclonal rearrangement of the immunoglobulin heavy chain gene locus. Thus, the diagnosis of a monoclonal, monomorphic EBV-associated B-cell PTLD was made. Of note, focal areas of necrosis (fig. 1a: arrow head) and extensive apoptotic activity with many macrophages engulfing apoptotic nuclear bodies (fig. 1b, c, e, f) were found. The B-cell proliferation was accompanied by an extensive CD3-positive T-cell infiltrate (fig. $1 \mathrm{j}$ ) consisting predominantly of $\mathrm{CD} 8$ /perforin/granzymeB- positive cytotoxic T-cells (fig. $1 \mathrm{k}-\mathrm{m}$ ) with only very few CD4 positive cells present (fig. 1n). Chimerism testing showed that $\mathrm{T}$-and B-cells, found in the lymph node, were $100 \%$ of donor origin.

CT-scans taken 1 week after biopsy showed regression of lymphadenopathy. Virological testing was finally negative for EBV and CMV. The patient achieved complete remission and was discharged 1 month after initial development of lymphadenopathy.

Two months later the patient was referred again to the hospital with diarrhoea and emesis, fever and 
shivering due to severe GvHD grade II. Despite intensive therapy the general condition of the patient worsened. He developed septicaemia and he became somnolent due to encephalopathy. He developed severe pulmonary oedema and died 12 months after initial diagnosis of ALL and 3 months after initial diagnosis of PTLD due to multi-organ failure.

At post-mortem examination, no residues of ALL or PTLD were found. The bone marrow was significantly hypocellular with a dramatic reduction of all three hematopoietic cell lines. Evidence of GvHD was found in stomach, small intestine and colon, and there were disseminated hyaline micro-thrombi in lungs and myocardium. Petechial bleeding was seen in small intestine, ileum and colon and there was extensive hemorrhage in the spleen. In addition, there was biventricular cardiac hypertrophy and evidence of congestive heart failure.

\section{Discussion}

EBV-associated PTLD is an important complication of stem cell transplantation. In healthy individuals, primary EBV infection induces a virus-driven B-cell proliferation which may manifest clinically as infectious mononucleosis and which eventually is controlled by the development of a virus-specific T-cell immunity. This is directed against virus-encoded lytic and latent proteins and allows the establishment of life-long virus persistence in memory B-cells.

While virus persistence remains asymptomatic in the vast majority of individuals, occasionally EBV-associated tumours may develop, mostly of lymphoid origin. It is generally assumed that some degree of failure of the immune system to control EBV infection is involved in the pathogenesis of these neoplasms [5]. This failure may be in the microenvironment of the tumour cells. E.g., it is assumed that modulation of local immune reactions by cytokines produced in the tumour cells contributes to the development of EBV-associated Hodgkin lymphoma. On the other hand, failure of EBVspecific immunity may be systemic, as in transplant recipients subjected to iatrogenic immunosuppression [5]. The notion that failure of T-cell control of EBV infection is a crucial factor in the pathogenesis of PTLD is supported by several observations. PTLD cells frequently express EBV-encoded latent proteins, including EBNA2, which are recognised by EBV-specific T-cells in immunocompetent individuals [6]. Moreover it has long been known that PTLDs may regress upon reduction or withdrawal of immunosuppressive therapy [7]. Also, EBVspecific cytotoxic $T$-cells may induce regression of the outgrowth of EBV-transformed B-cells in vitro and this effect is abolished by cyclosporine A [8]. Finally, adoptive transfer of EBV-specific T-cells has proved successful in the treatment and prevention of PTLD [9].
Here we present, to our knowledge, the first description of the histopathological features of PTLD regression following reduction of immunosuppressive therapy. These were characterised by two main features. We demonstrate an intense infiltration of the affected lymph node by cytotoxic T-cells expressing CD8, perforin, and granzymeB. In addition, we observed extensive apoptosis of blast cells. The resulting apoptotic nuclear bodies were phagocytosed by macrophages. The latter feature is reminiscent of, e. g., Burkitt lymphoma and in germinal centre reactions, where a a high cellular turnover is accompanied by intense apoptotic activity. Although we cannot prove this directly, in the context of previous studies cited above, our results strongly suggest that apoptotic regression of the neoplastic EBV-positive B-cells was triggered by the re-emergence of EBV-specific T-cells in this case. This notion is well in line with current understanding of EBV-specific T-cell immunity [10]. In contrast, e. g. in Burkitt lymphoma a high spontaneous apoptotic rate is observed in the absence of cytotoxic T-cells. This might be related to the absence of antiapopotic factors such as bcl-2, which typically is not expressed in Burkitt lymphoma. Similarly, in physiological germinal centre reactions, in the absence of bcl-2 expression apoptosis is triggered by a lack of survival signals rather than cytotoxic activity of T-cells.

This role of cytotoxic T-cells in the control of EBV infection explains, why $\mathrm{T}$-cell depletion via antithymocyte globulin or anti-CD3 monoclonal antibodies represents a major risk factor for the development of EBVassociated PTLD [4,11-13]. As the use of HLA-mismatched donor transplants usually requires more intensive immunosuppression, this additionally increases the risk for developing PTLD. Also, children and teenagers are at high risk of developing PTLD [14], most likely because an adequate primary immune response to EBV infection cannot be mounted under immunosuppressive therapy and because patients of this age group are frequently EBV seronegative before transplantation [15].

Although regression of PTLD following reduction or withdrawal of immunosuppressive therapy has been reported previously, the prognosis generally remains poor and treatment now includes rituximab and chemotherapy $[16,17]$. In our case, reduction of immunosuppression without further treatment led to a reduction of lymphadenopathy with full clinical remission accompanied by the development of GvHD. Patients with PTLD following stem cell transplantation usually die from progressive EBV-associated lymphoproliferation, sepsis, severe GvHD or relapse of the underlying haematological malignancy [18]. In our case, combined sepsis and GvHD were the leading causes of death and post mortem examination confirmed complete remission of PTLD. 
In summary, we present a case of a case of PTLD after stem cell transplantation with complete remission following reduction of immunosuppressive therapy. We were able to show for the first time to our knowledge the histomorphological features occurring in PTLD lymph nodes in this scenario which are characterised by apoptotic cell death of EBV-infected B-blasts triggered by cytotoxic-T-cells.

\author{
Author details \\ 'Institute of Pathology, University of Leipzig, Liebigstr. 26, 04103 Leipzig, \\ Germany. ${ }^{2}$ Division of Hematology and Oncology, University of Leipzig, \\ Johannisallee 32, 04103 Leipzig, Germany. ${ }^{3}$ Institute of Pathology, Sana \\ Klinikum Lichtenberg and Unfallkrankenhaus Berlin, Fanningerstr. 32, 10365 \\ Berlin, Germany.
}

\section{Authors' contributions}

AK collected the data and was the main author of the manuscript. AM helped with evaluting the data. WP and DN were the treating oncologist. NS contributed to writing up the manuscript. GN was the consiliary pathologist. TA was the senior supervisor of the work performed. All authors read and approved the final manuscript.

\section{Competing interests}

The authors declare that they have no competing interests.

Received: 22 November 2009 Accepted: 31 March 2010

Published: 31 March 2010

\section{References}

1. Epstein MA, Achong BG, Barr YM: VIRUS PARTICLES IN CULTURED LYMPHOBLASTS FROM BURKITT'S LYMPHOMA. Lancet 1964, 1:702-703.

2. Loren AW, Porter DL, Stadtmauer EA, Tsai DE: Post-transplant lymphoproliferative disorder: a review. Bone Marrow Transplant 2003, 31:145-155.

3. Hsieh WS, Lemas MV, Ambinder RF: The biology of Epstein-Barr virus in post-transplant lymphoproliferative disease. Transpl Infect Dis 1999, 1:204-212.

4. Harris NL, Ferry JA, Swerdlow SH: Posttransplant lymphoproliferative disorders: Summary of Society for Hematopathology Workshop. Semin Diagn Pathol 1997, 14:8-14.

5. Niedobitek $G$, Young LS, Herbst H: Epstein-Barr virus infection and the pathogenesis of malignant lymphomas. Cancer Surveys 1997, 30:143-162.

6. Rowe M, Niedobitek G, Young LS: Epstein-Barr virus gene expression in post-transplant lymphoproliferative disorders. Springer Semin Immunopathol 1998, 20:389-403.

7. Starzl TE, Nalesnik MA, Porter KA, Ho M, Iwatsuki S, Griffith BP, Rosenthal JT, Hakala TR, Shaw BW Jr, Hardesty RL: Reversibility of lymphomas and lymphoproliferative lesions developing under cyclosporin-steroid therapy. Lancet 1984, 1:583-587.

8. Rickinson AB, Rowe M, Hart IJ, Yao QY, Henderson LE, Rabin H, Epstein MA: T-cell-mediated regression of "spontaneous" and of Epstein-Barr virusinduced B-cell transformation in vitro: studies with cyclosporin A. Cell Immunol 1984, 87:646-658.

9. Heslop HE, Savoldo B, Rooney CM: Cellular therapy of Epstein-Barr-virusassociated post-transplant lymphoproliferative disease. Best Pract Res Clin Haematol 2004, 17:401-413.

10. Hislop AD, Taylor GS, Sauce D, Rickinson AB: Cellular responses to viral infection in humans: lessons from Epstein-Barr virus. Annu Rev Immunol 2007, 25:587-617.

11. Mentzer SJ, Perrine SP, Faller DV: Epstein-Barr virus post-transplant lymphoproliferative disease and virus-specific therapy: pharmacological re-activation of viral target genes with arginine butyrate. Transpl Infect Dis 2001, 3:177-185.

12. Davis CL, Wood BL, Sabath DE, Joseph JS, Stehman-Breen C, Broudy VC: Interferon-alpha treatment of posttransplant lymphoproliferative disorder in recipients of solid organ transplants. Transplantation 1998, 66:1770-1779.

13. Salazar-Mather TP, Ishikawa R, Biron CA: NK cell trafficking and cytokine expression in splenic compartments after IFN induction and viral infection. J Immunol 1996, 157:3054-3064

14. Ho M, Jaffe R, Miller G, Breinig MK, Dummer JS, Makowka L, Atchison RW, Karrer F, Nalesnik MA, Starzl TE: The frequency of Epstein-Barr virus infection and associated lymphoproliferative syndrome after transplantation and its manifestations in children. Transplantation 1988, 45:719-727.

15. Davis JE, Moss DJ: Treatment options for post-transplant lymphoproliferative disorder and other Epstein-Barr virus-associated malignancies. Tissue Antigens 2004, 63:285-292.

16. Blaes AH, Peterson BA, Bartlett N, Dunn DL, Morrison VA: Rituximab therapy is effective for posttransplant lymphoproliferative disorders after solid organ transplantation: results of a phase II trial. Cancer 2005, 104:1661-1667.

17. Gottschalk S, Rooney CM, Heslop HE: Post-transplant lymphoproliferative disorders. Annu Rev Med 2005, 56:29-44.

18. Ocheni S, Kroeger N, Zabelina T, Sobottka I, Ayuk F, Wolschke C, Muth A, Lellek H, Petersen L, Erttmann R, Kabisch H, Zander AR, Bacher U: EBV reactivation and post transplant lymphoproliferative disorders following allogeneic SCT. Bone Marrow Transplant 2008, 42:181-186.

\section{doi:10.1186/1746-1596-5-21}

Cite this article as: Krenauer et al: EBV-associated post-transplantation B-cell lymphoproliferative disorder following allogenic stem cell transplantation for acute lymphoblastic leukaemia: tumor regression after reduction of immunosuppression - a case report. Diagnostic Pathology 2010 5:21.

\section{Submit your next manuscript to BioMed Central and take full advantage of:}

- Convenient online submission

- Thorough peer review

- No space constraints or color figure charges

- Immediate publication on acceptance

- Inclusion in PubMed, CAS, Scopus and Google Scholar

- Research which is freely available for redistribution

Submit your manuscript at www.biomedcentral.com/submit
C Biomed Central 